\title{
Two Novel Approaches Used to Produce Biodiesel from Low-Cost Feedstocks
}

\author{
Xiaohu Fan ${ }^{*}, 1$ Xi Wang ${ }^{2}$ and Feng Chen ${ }^{1}$ \\ ${ }^{I}$ Department of Food Science and Human Nutrition, Clemson University, Clemson, SC 29634, USA \\ ${ }^{2}$ Department of Genetics and Biochemistry, Clemson University, Clemson, SC 29634, USA
}

\begin{abstract}
The price of feedstock is one of the most significant factors affecting the economic viability of biodiesel manufacturer. Many approaches were investigated to reduce the biodiesel production cost. The present work gave a preliminary study of two approaches to economically produce biodiesel from waste cooking oil (WCO) and flaked cottonseed. One was the use of ultrasound-assisted synthesis of biodiesel from WCO. The other was the application of in situ transesterification from flaked cottonseed. Gas chromatography (GC) and High performance liquid chromatography (HPLC) results demonstrated the feasibility of using both approaches to produce biodiesel from low-cost feedstock.
\end{abstract}

Keywords: Biodiesel, waste cooking oil, flaked cottonseed, ultrasound-assisted synthesis, in situ transesterification.

\section{INTRODUCTION}

As a notable alternative to the widely used petroleumderived diesel fuel, biodiesel receives a lot of attention. Biodiesel can reduce lifecycle greenhouse gas emissions since it is largely made from vegetable oils [1]. More important, biodiesel can also reduce the dependence on diminishing petroleum fuel from foreign sources due to the fact that it can be produced by domestic natural sources, such as soybean oil, palm oil, and rapeseed oil etc.

Despite the advantages mentioned above, the cost of biodiesel is higher than petroleum-based diesel and this has been a major barrier to its commercialization. One of the ways widely accepted for reducing the cost focuses on minimizing the raw material cost [2]. The utilization of lowcost feedstock, such as waste cooking oil (WCO), can not only solve the problem of waste oil disposal, but generate environmentally benign fuel. Biodiesel can be synthesized from waste oil by using commonly used approach, including acid [3], alkaline [4] and enzyme [5,6] catalyses.

In addition, the selection of novel approach can also save biodiesel overall production cost, making biodiesel more competitive with petroleum diesel. One approach is to utilize ultrasound-assisted approach to synthesize biodiesel from low cost non-edible oils feedstocks, such as WCO. Nowadays, low frequency ultrasonication receives more and more interest for biodiesel production [7-10]. It was proved to be an efficient, energy saving and economically feasible way. This process can enhance the mass transfer between two immiscible liquids, methanol and oils through cavitation. The application of ultrasound on biodiesel production from WCO will further reduce the biodiesel production cost.

Another approach is to use in situ transesterification process to produce biodiesel. By using this approach, the

*Address correspondence to this author at the Department of Food Science and Human Nutrition, Clemson University, Clemson, SC 29634, USA; Tel: 1864-656-1291; Fax: 1-864-656-0331; E-mail: xfan@biofuels.coop transesterification reagents might be able to access triglycerides resident in oilseeds and achieve their transesterification directly. This could simplify the whole reaction steps since solvent extraction and oil cleanup prior to biodiesel synthesis become unnecessary. Many researchers investigated this approach for biodiesel production. Georgogianni et al. compared in situ transesterification of both sunflower seed oil [11] and cottonseed oil [12] with conventional transesterification. The authors found that in situ transesterification gave similar ester yields to those obtained by conventional transesterification, which indicated the former method could be an alternative, efficient and economical process. Hass et al. [13] made a reasonable conclusion that in situ approach might be valid for the production of biodiesel from virtually any lipid-bearing material after the authors explored the general applicability of this approach to feedstocks other than soybeans, such as distillers dried grains with solubles, the co-product of the production of ethanol from corn, and meat and bone meal, a product of animal rendering.

The present work simply showed a preliminary study of the use of WCO as raw material for biodiesel production assisted by using $40 \mathrm{kHz}$ ultrasonic irradiation. Meanwhile, in situ alkaline transesterification of flaked cottonseed was further investigated.

\section{MATERIALS AND METHODOLOGY}

\subsection{Materials and Equipment}

Methanol and sodium hydroxide were purchased from Fisher Scientific (Suwanee, GA, USA). WCO was obtained from New China restaurant (Clemson, SC, USA). Every day this restaurant produces many WCO which is used for cooking various Chinese dishes. So the WCO may contain some food particles, phospholipids etc. Identification of fatty acids composition of WCO was performed by comparison of retention times with fatty acid standard purchased from SUPELCO (Supelco park, Bellefonte, PA, USA). The ultrasonic system is comprised of ultrasound reactor, power supply amplifier (Model G 7520), and function generator (Model 182A), which converts a standard line voltage to a 
high-frequency electrical power. This electrical energy fed to the transducer, which is inside the soundproof enclosure, can be converted to mechanical vibrations of the same frequency.

\subsection{Fatty acid profile of WCO}

Shimadzu's GC-Flame ignited detector (FID) system was used for the analyses of fatty acid profile of the WCO. It consists of a GC-17A, a flame ionization detector, and a DBWAX capillary column $(60 \mathrm{~m}, 0.25 \mathrm{~mm}$, thickness $=0.25 \mu \mathrm{m}$; $\mathrm{J} \& \mathrm{~W}$ Scientific). The initial temperature for oven was set at $140{ }^{\circ} \mathrm{C}$ and held for $5 \mathrm{~min}$. Then the temperature increased from $140{ }^{\circ} \mathrm{C}$ to $220^{\circ} \mathrm{C}$ at the ramp of $4^{\circ} \mathrm{C} / \mathrm{min}$ and held at $220^{\circ} \mathrm{C}$ for $25 \mathrm{~min}$. The injector and detector were maintained at $200^{\circ} \mathrm{C}$ and $220^{\circ} \mathrm{C}$, respectively. Helium was used as a carrier gas and the split ratio was 50/1. Supelco ${ }^{\mathrm{TM}} 37$ Component Fatty acid methyl ester (FAME) Mix was as the standard.

\subsection{Water Determination}

The water content was measured by direct coulometric Karl Fischer titration according to ISO 12937(2000) using the 756 KF Coulometer (Metrohm Company, Switzerland). The water content in the WCO was $0.1 \%$.

\subsection{Ultrasound-Assisted Synthesis of Biodiesel from WCO}

Before transesterification, the WCO was filtered under vacuum to remove any solid impurities. Free fatty acid (FFA) content of the WCO was measured according to A.O.C.S. Official Method Ca 5a-40.

FFA content was $2.8 \%$, calculated as oleic acid. According to Gerpen [14], the transesterification reaction can still be catalyzed with an alkaline catalyst up to about 5\% FFAs, but additional catalyst must be added to compensate for the catalyst lost to soap. Since the acid-catalyzed pretreatment of WCO will increase the operation cost, direct alkaline-catalysis is preferred. Extra alkaline (sodium hydroxide) was added to neutralize the FFAs. This mixture was then introduced to the ultrasound reactor. Ultrasound reaction was started at $40 \mathrm{kHz}$. After reaction, the product was kept overnight. The glycerol richer-phase, which stayed in the lower layer due to its relatively higher density, was separated from the methyl ester (biodiesel) layer, the upper layer. The methyl ester layer was then washed to remove the excess alcohol residue, catalyst, and soap. Since water in biodiesel can lead to biological growth, the washed biodiesel was placed at $55^{\circ} \mathrm{C}$ oven to evaporate the water residue and then dried with anhydrous sodium sulphate.

\subsection{In Situ Transesterification of Flaked Cottonseed}

Flaked cottonseeds were first dried overnight in the oven at about $70 \sim 77^{\circ} \mathrm{C}$ to remove the moisture and then mixed with methanol in which sodium hydroxide were already dissolved. The mixtures were placed in the capped bottle, sealed tightly. The molar ratio of methanol/oil/ $\mathrm{NaOH}$ for the flaked cottonseed as the raw material was equal to $543 / 1 / 2$ [15]. The bottle (contained sample) was placed at Roto mixer. Mixing of the methanol and flaked cottonseed was conducted like orbital shaking. The reaction was performed at room temperature. Sufficient speed was maintained to keep the flaked cottonseed well suspended.

\section{RESULTS AND DISCUSSION}

Figs. $(1,2)$ show the GC chromatogram of Supelco ${ }^{\mathrm{TM}} 37$ Component FAME Mix Standard and fatty acid profile of WCO, respectively. By comparing with the known fatty acid profile of the FAME mix standard, it can be concluded that WCO primarily contains palmitic acid (C16:0), oleic acid (C18:1), and linoleic acid (C18:2). Ultrasound-assisted

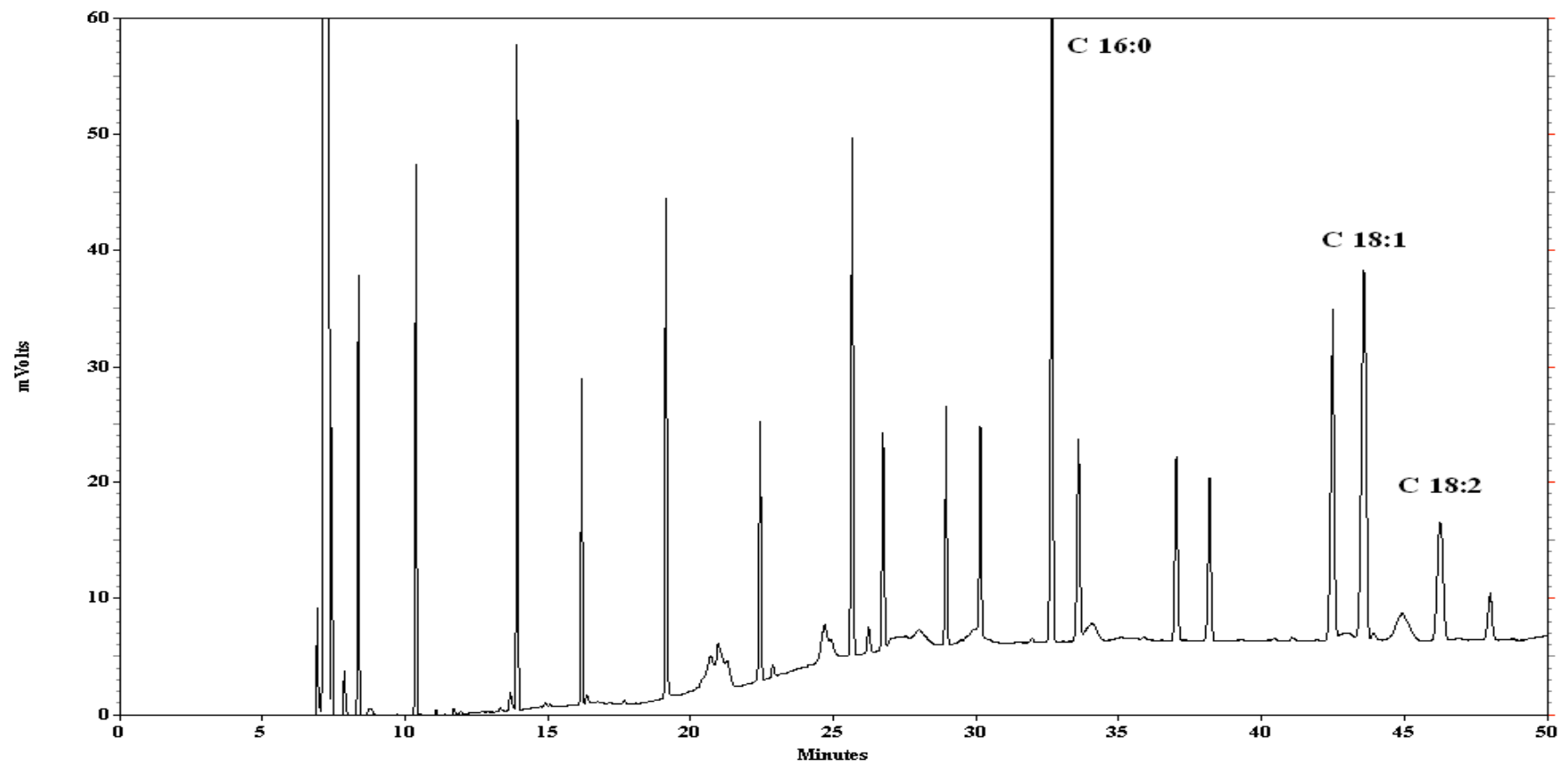

Fig. (1). GC chromatogram of Supelco ${ }^{\mathrm{TM}} 37$ component FAME mix standard. 


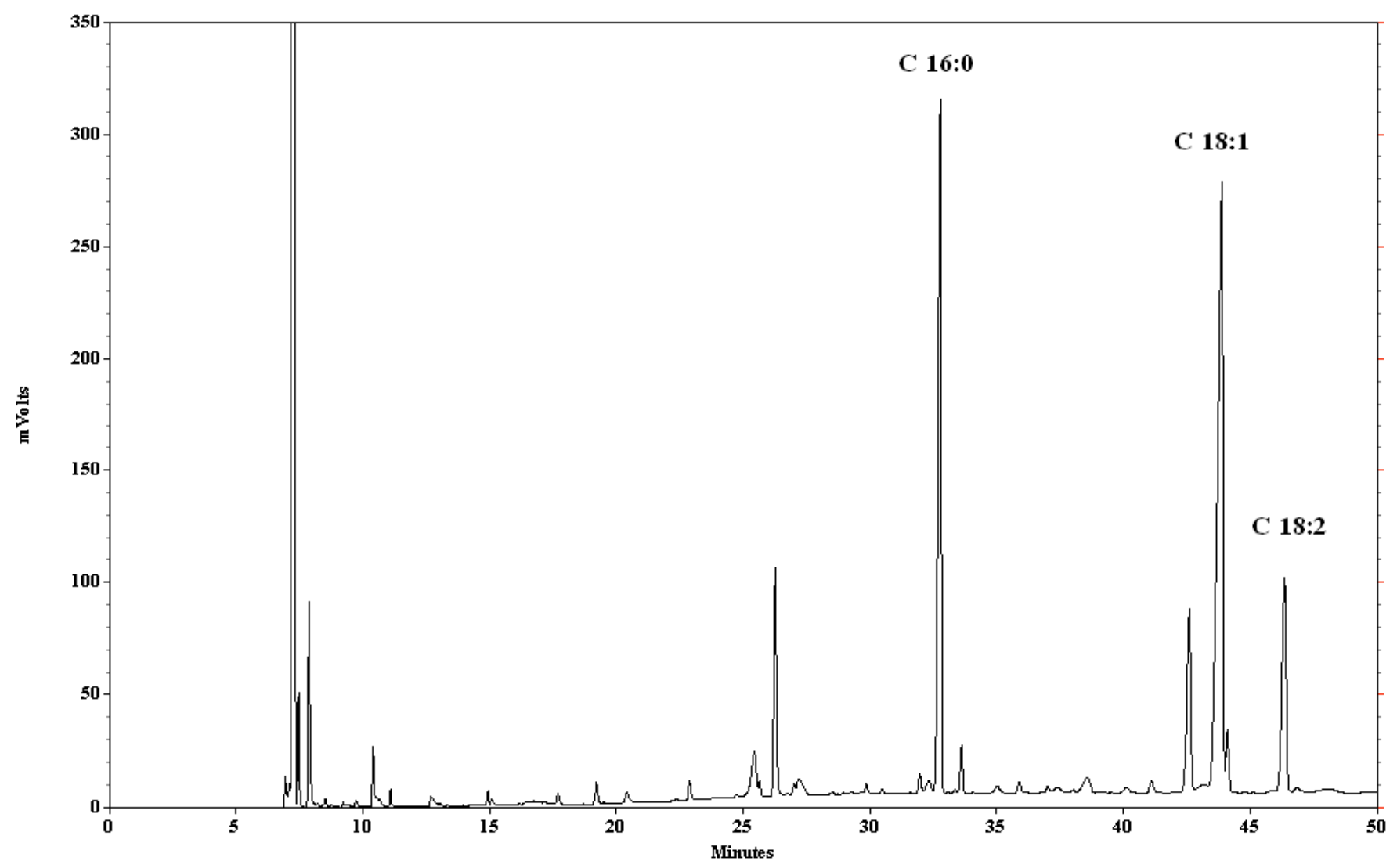

Fig. (2). Fatty acid profile of WCO.

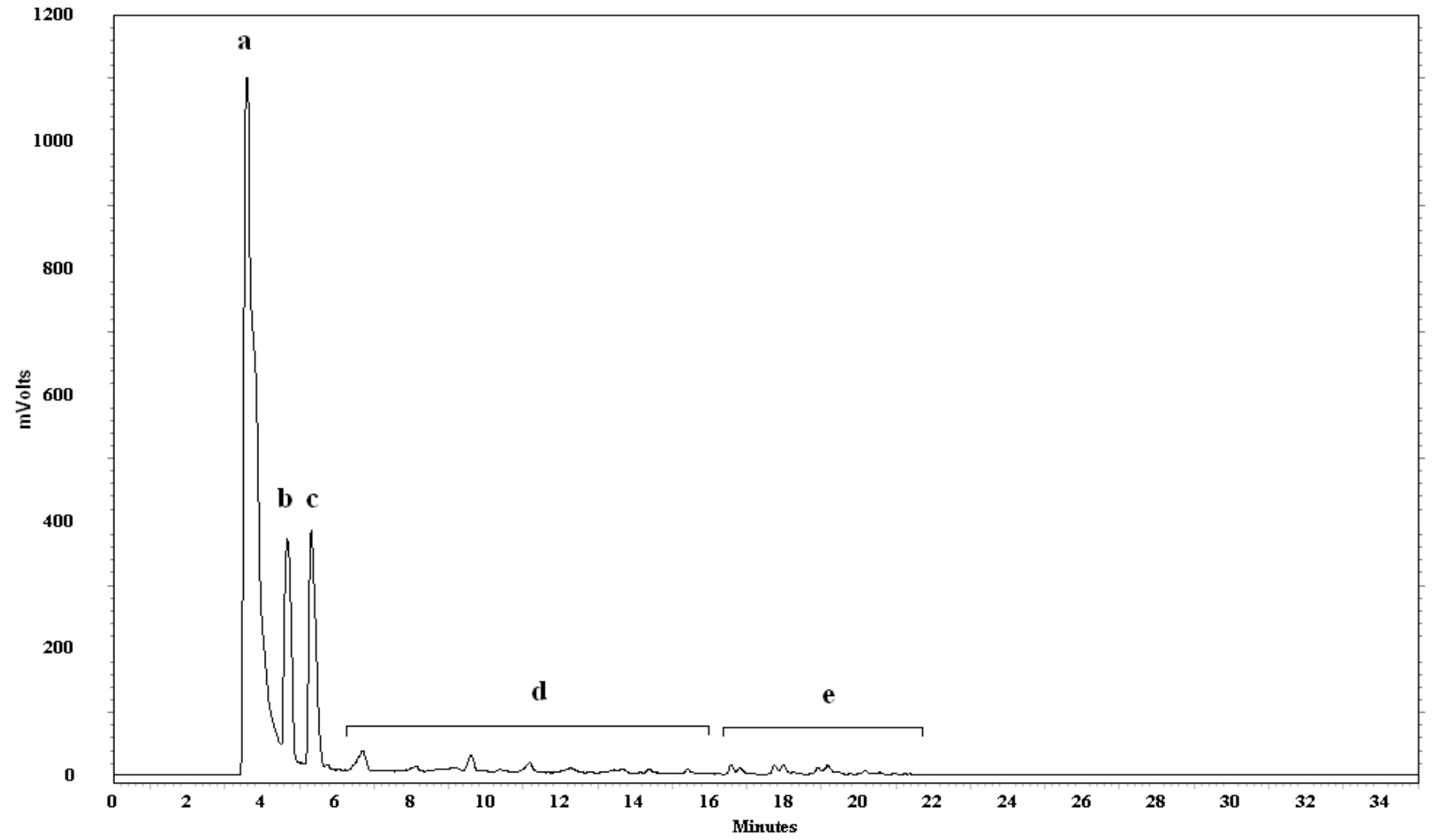

Fig. (3). HPLC chromatogram of biodiesel produced by ultrasound-assisted transesterificaiton of WCO a C18:1 (oleic acid methyl ester), b C18:2 (linoleic acid methyl ester), c C16:0 (palmitic acid methyl ester), d diglycerides, e unreacted triglycerides present in the biodiesel. 


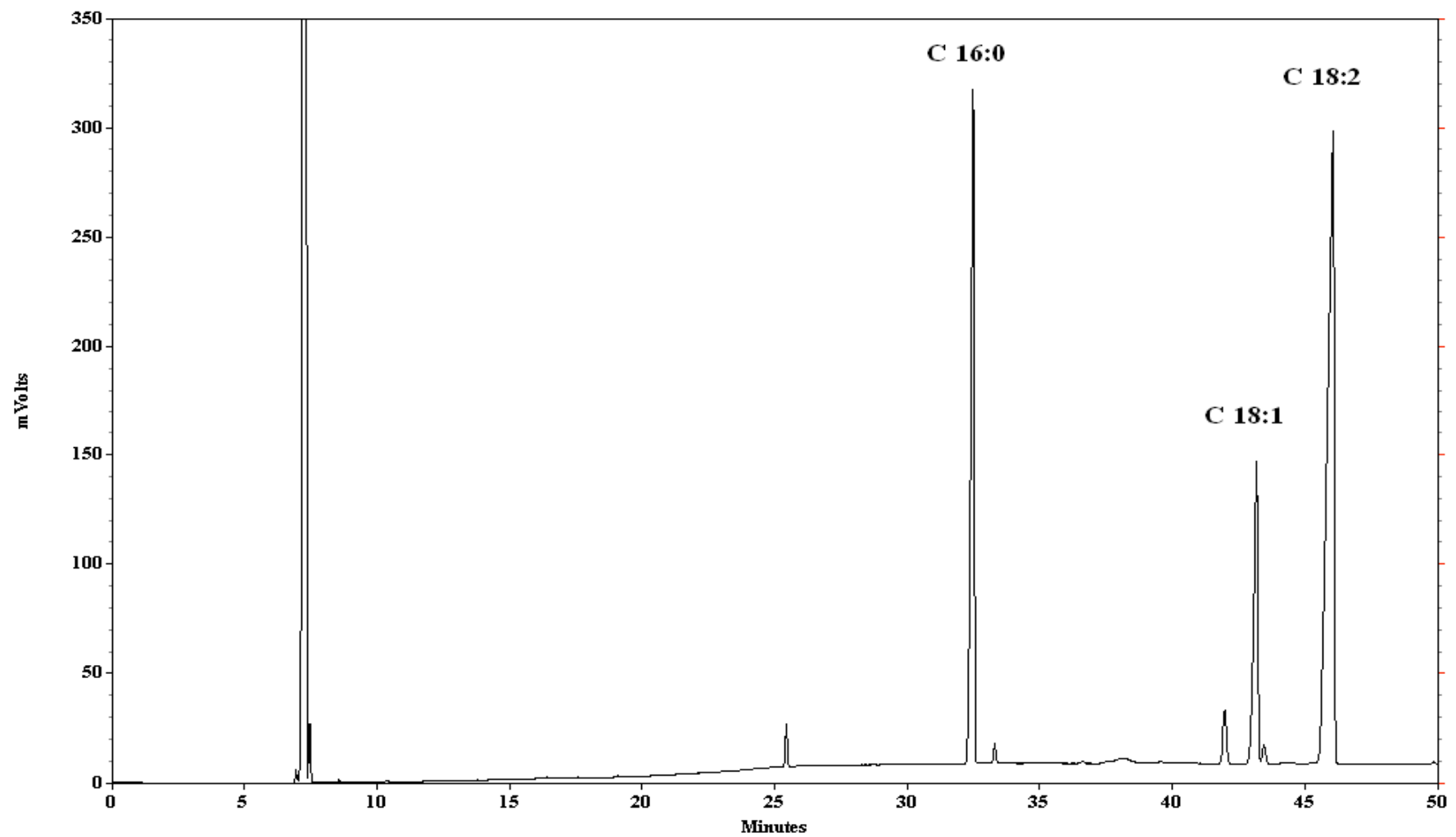

Fig. (4). GC Chromatogram of biodiesel produced by in situ transesterification of flaked cottonseed.

transesterification of WCO was performed at $1 \%$ catalyst concentration, 6/1 molar ratio of methanol to oil, $8 \mathrm{~min}$ reaction time and room temperature. The advantage of using ultrasound-assisted approach to produce biodiesel was attributed to the effect of cavitation, in which strong shock wave generated during the collapse of bubbles further disrupts the phase boundary, enhancing the mixing efficiency between immiscible triglycerides and alcohols. It can be seen from Fig. (3) that after ultrasound-assisted transesterificaiton, only very small diglycerides and triglycerides peaks appear, demonstrating high conversion.

As comparison, in situ transesterification is another novel approach for generating biodiesel. In this preliminary study, in situ transesterificaiton of flaked cottonseed was carried out in $9 \mathrm{~h}$ at the molar ratio of 543:1:2 for methanol/oil/NaOH. Fig. (4) shows GC chromatogram of biodiesel produced by in situ transesterificaiton approach. Though large amount of methanol is needed, this approach can process low-cost feedstock, that is, flaked cottonseed, without using solvent extraction process. With further extensive research, it may be possible in the industrial scale to get high yield biodiesel directly from oilseed.

\section{CONCLUSIONS}

In this study, two novel approaches (ultrasound-assisted transesterificaiton and in situ transesterification) were investigated to transesterify low-cost feedstocks, including WCO and flaked cottonseed. It was found that by applying ultrasound-assisted approach, WCO could be converted to biodiesel with high conversion at these conditions: $1 \%$ catalyst concentration, 6/1 methanol to WCO molar ratio, 8 min reaction time and room temperature. Meanwhile, preliminary study showed that flaked cottonseed can be converted to methyl esters by in situ transesterificaiton, which can be served as the basis for further extensive research.

\section{ACKNOWLEDGEMENTS}

The authors are grateful to the Cotton Inc. and the Clemson University Vice President Research Fund for the financial support.

\section{REFERENCES}

[1] Fan, X.H.; Wang, X.; Chen, F. Engine performance test of cottonseed oil biodiesel. Fuels Energ. Sci. J., 2008, 1, 40-45.

[2] Fan, X.H.; Burton, R. Recent development of biodiesel feedstocks and the applications of glycerol: a review. Fuels Energ. Sci. J., 2009, 1, 100-109.

[3] Zheng, S.; Kates, M.; Dubé, M.A.; McLean, D.D. Acid-catalyzed production of biodiesel from waste frying oil. Biomass Bioenerg., 2006, 30, 267-272.

[4] Encinar, J.M.; González, J.F.; Rodríguez-Reinares, A. Biodiesel from used frying oil. Variables affecting the yields and characteristics of the biodiesel. Ind. Eng. Chem. Res., 2005, 44, 5491-5499.

[5] Watanabe, Y.; Shimada, Y.; Sugihara, A.; Tominaga, Y. Enzymatic conversion of waste edible oil to biodiesel fuel in a fixed-bed bioreactor. J. Am. Oil Chem. Soc., 2001, 78(7), 703-707.

[6] Chen, G.; Ying, M.; Li, W.Z. Enzymatic conversion of waste cooking oils into alternative fuel-biodiesel. Appl. Biochem. Biotechnol., 2006, 129-132, 911-921.

[7] Stavarache, C.; Vinatoru, M.; Maeda, Y. Ultrasonic versus silent methylation of vegetable oils. Ultrason. Sonochem., 2006, 13, 401407.

[8] Armenta, R.E.; Vinatoru, M.; Burja, A.M.; Kralovec, J.A.; Barrow, C.J. Transesterification of fish oil to produce fatty acid ethyl esters using ultrasonic energy. J. Am. Oil Chem. Soc., 2007, 84, $1045-$ 1052. 
[9] Stavarache, C.; Vinatoru, M.; Nishimura, R.; Maeda, Y. Fatty acids methyl esters from vegetable oil by means of ultrasonic energy. Ultrason. Sonochem., 2005, 12, 367-372.

[10] Hanh, H.D.; Dong, N.T.; Starvarache, C.; Okitsu, K.; Maeda, Y.; Nishimura, R. Methanolysis of triolein by low frequency ultrasonic irradiation. Energy Convers. Manage., 2008, 49, 276-280.

[11] Georgogianni, K.G.; Kontominas, M.G.; Pomonis, P.J.; Avlonitis, D.; Gergis, V. Conventional and in situ Transesterification of sunflower seed oil for the production of biodiesel. Fuel Process. Technol., 2008, 89, 503-509.

[12] Georgogianni, K.G.; Kontominas, M.G.; Pomonis, P.J.; Avlonitis, D.; Gergis, V. Alkaline conventional and in situ transesterification of cotttonseed oil for the production of biodiesel. Energ. Fuel., 2008, 22, 2110-2115.

[13] Haas, M.J.; Scott, K.M.; Foglia, T.A.; Marmer, W.N. The general applicability of in situ transesterification for the production of fatty acid esters from a variety of feedstocks. J. Am. Oil Chem. Soc., 2007, 84, 963-970.

[14] Gerpen, J.V. Biodiesel Processing and Production. Fuel Process. Technol., 2005, 86, 1097-1107.

[15] Haas, M.J.; Scott, K.M.; Marmer, W.N.; Foglia, T.A. In Situ alkaline transesterification: an effective method for the production of fatty acid esters from vegetable oils. J. Am. Oil Chem. Soc., 2004, 81, 83-89.

(C) Fan et al.; Licensee Bentham Open.

This is an open access article licensed under the terms of the Creative Commons Attribution Non-Commercial License (http://creativecommons.org/licenses/by$\mathrm{nc} / 3.0 /$ ) which permits unrestricted, non-commercial use, distribution and reproduction in any medium, provided the work is properly cited. 